\title{
Avaliação dos Impactos Ambientais do Vazadouro Municipal de Volta Redonda-RJ após sua Desativação
}

\author{
Evaluation of Environmental Impacts from the Municipal Dump of Volta Redonda-RJ \\ after its Deactivation
}

\section{Evaluación de los Impactos Ambientales del Vertedero Municipal de Volta Redonda- $R J$ tras su Desactivación}

\author{
Bruno Rocha Silva Setta ${ }^{1}$ \\ Ana Cristina Malheiros Gonçalves Carvalho² \\ Maria José Lopes de Araujo Saroldi ${ }^{3}$
}

RESUMO: Diante do acelerado crescimento populacional nas cidades, sobretudo de países emergentes, como o Brasil, a alternativa economicamente viável para a destinação final dos resíduos foi a construção de vazadouros a céu aberto, popularmente conhecidos como lixões. No entanto, este tipo de disposição de resíduos não é considerado ambientalmente adequado, pois pode provocar impactos à saúde pública e ao meio ambiente, tais como: a produção de chorume, líquido altamente tóxico, a emissão do gás metano e atração de animais vetores de doenças, entre outros. Dispositivos legais, como o TAC, e métodos de avaliação de impactos ambientais têm sido aplicados com objetivo de minimizar os impactos ambientais e possibilitar um potencial uso harmônico e saudável da área degradada para a população e ao meio ambiente. Neste sentido, este trabalho buscou analisar os impactos ambientais da área do vazadouro do Município de Volta Redonda, localizado no interior do Estado do Rio de Janeiro, com o intuito de avaliar sua recuperação ambiental. Para tanto, foram realizadas entrevistas com técnicos da secretaria do meio ambiente do município, órgãos públicos ambientais, levantamento bibliográfico da área de estudo e visitas de campo no local. Verificou-se que o vazadouro operou desde 1987 até 2012, gerando impactos ambientais significativos na sua área e no seu entorno, como a eutrofização do lago a montante, erosão do talude e contaminação do Rio Brandão por chorume. Após sua desativação, verificaram-se melhorias no local, como a regeneração da vegetação, restabelecimento da fauna, sobretudo de aves, e instalações construídas e direcionadas para a remediação ambiental.

PALAVRAS-CHAVE: Avaliação de impactos ambientais. Vazadouro. Volta Redonda (RJ).

\footnotetext{
1 Pontifícia Universidade Católica do Rio de Janeiro. Rua Marquês de São Vicente, nº 225 - Sala 301L, CEP 22451-900 - Rio de Janeiro - RJ. E-mail: brunosetta@hotmail.com.

2 Departamento de Engenharia Civil da PUC-Rio. Rua Marquês de São Vicente, no 225 - Sala 301L, CEP 22451-900 - Rio de Janeiro - RJ. E-mail: anacris@puc-rio.br.

${ }^{3}$ Departamento de Engenharia Civil da PUC-Rio. Rua Marquês de São Vicente, nº 225 - Sala 301L, CEP 22451-900 - Rio de Janeiro - RJ. E-mail: saroldi@globo.com.
} 
ABSTRACT: Due to the accelerated population growth in cities, especially in emerging countries, such as Brazil, the economically viable alternative to the final disposal of waste was the construction of landfills, popularly known as dumps. However, this type of waste disposal is not considered environmentally appropriate, as it may cause impacts on public health and the environment, such as: slurry production, highly toxic liquid, methane gas emission, attraction of disease vectors, among others. Legal provisions, such as TACs, and environmental impact assessment methods have been applied with the aim to minimize environmental impacts and enabling harmonic and healthy use of the degraded area for population and environment. In this sense, the objective of this work was to evaluate the environmental impacts from the municipal dump area of Volta Redonda, located in the interior of Rio de Janeiro State, to evaluate its environmental recovery. For this, interviews were carried out with technicians from the Municipal Environment Department, public environmental agencies, bibliographic survey of the study area and field visits at the site. It was verified that the dump operated from 1987 to 2012, generating significant environmental impacts in its area and not in its surroundings, such as eutrophication of the upstream lake, soil erosion and contamination of the Brandão River by mud. However, there were improvements at the site, such as regeneration of vegetation, restoration of fauna, especially birds, and facilities built and directed to environmental remediation.

KEYWORDS: Environmental impact assessment. Dump. Volta Redonda (RJ).

RESUMEN: Ante el acelerado crecimiento poblacional en las ciudades, sobre todo de países emergentes, como Brasil, la alternativa económicamente viable para el destino final de los residuos fue la construcción de vertederos a cielo abierto, popularmente conocidos como basurales. Sin embargo, este tipo de disposición de residuos no es considerado ambientalmente adecuado, pues puede provocar impactos a la salud pública y al medio ambiente, tales como: la producción de estiércol, líquido altamente tóxico, la emisión del gas metano y atracción de animales vectores de animales enfermedades, entre otros. Los dispositivos legales, como el TAC, y los métodos de evaluación de impactos ambientales, han sido aplicados con el objetivo de minimizar los impactos ambientales y posibilitar un potencial uso armónico y saludable del área degradada para la población y el medio ambiente. En este sentido, este trabajo buscó analizar los impactos ambientales del área del vertedero del Municipio de Volta Redonda, ubicado en el interior del Estado de Río de Janeiro, con el objetivo de evaluar su recuperación ambiental. Para ello, se realizaron entrevistas con técnicos de la secretaría del medio ambiente del municipio, organismos públicos ambientales, levantamiento bibliográfico del área de estudio y visitas de campo en el local. Se verificó que el vertedero operó desde 1987 hasta 2012, generando impactos ambientales significativos en su área y en su entorno, como la eutrofización del lago ascendente, erosión del talud y contaminación del Río Brandão por chorume. Después de su desactivación, se verificaron mejoras en el local, como la regeneración de la vegetación, restablecimiento de la fauna, sobre todo de aves, e instalaciones construidas y direccionadas para la remediación ambiental.

PALABRAS CLAVES: Evaluación de impactos ambientales. Vertedero. Volta Redonda (RJ).

\section{INTRODUÇÃO}

Segundo o Panorama dos Resíduos Sólidos no Brasil (2015, p. 18-20) dos 79,9 milhões de toneladas produzidos no ano de 2015 no país, 72,5 milhões de toneladas foram coletados, demonstrando um índice de cobertura de coleta de 90,8\%. Há oito anos, este índice era de $62 \%$ e hoje já está próximo a países da União Europeia e aos Estados Unidos, com 99\% e 95\%, respectivamente (ANÁLISE..., 2012, p. 72-74). No entanto, o volume de 
resíduos enviados para destinação inadequada foi quase 30 milhões de toneladas, dispostos em lixões ou aterros controlados, os quais não apresentam as medidas necessárias de segurança para a proteção do meio ambiente contra danos e degradações.

$\mathrm{Na}$ maioria dos municípios brasileiros, a administração pública se limita ao recolhimento do lixo domiciliar, depositando-o em locais afastados da população e de maneira inadequada no ambiente (JUNKES, 2002). Além disto, muitos municípios brasileiros apresentam dificuldades para o destino adequado dos resíduos sólidos, tais como: precariedade da infraestrutura sanitária, falta de informações consistentes sobre dados sanitários, ausência de espaços físicos amplos para a construção de aterros sanitários e dificuldades financeiras, técnicas e estruturais para implantar o previsto na Lei no 12.305/2010 - Política Nacional de Resíduos Sólidos (BRASIL, 2010). As taxas de implantação de métodos nobres de tratamento de resíduos, como compostagem, incineração e reciclagem, ainda caminham lentamente (ASSAD; SIQUEIRA, 2016).

A disposição inadequada de resíduos em lixões e aterros controlados causa impactos ambientais significativos aos ecossistemas naturais e à saúde pública. De acordo com a Resolução CONAMA № 001, de 23 de janeiro de 1986 (BRASIL, 1986), o impacto ambiental pode ser definido como qualquer alteração das propriedades físicas, químicas e/ou biológicas do meio provocada, direta ou indiretamente, por atividades humanas que podem afetar a saúde pública, a segurança e/ou a qualidade ambiental dos recursos naturais.

Dentre os principais impactos ambientais ocasionados por lixões ou aterros controlados estão: a contaminação de mananciais superficiais e de lençóis freáticos por infiltração de lixiviados produzidos a partir do processo de decomposição da matéria orgânica, comprometendo seu uso domiciliar; erosão do solo pela compactação dos resíduos; e atração de vetores transmissores de doenças (JUNKES, 2002; SETTA, 2016). Além disto, segundo Gouveia (2012), estudos têm indicado que populações residentes nas proximidades desses locais apresentam níveis elevados de metais pesados e compostos orgânicos no sangue, o que pode torná-las vulneráveis a diversos tipos de câncer, anomalias congênitas e mortes neonatais precoces.

A Avaliação de Impacto Ambiental (AIA) torna-se um instrumento essencial da Política Nacional do Meio Ambiente (PNMA), Lei no 6.938/1981 (BRASIL, 1981), capaz de, a partir da identificação e avaliação da significância dos impactos decorrentes de um dado empreendimento, possibilitar aos entes envolvidos, sejam eles públicos ou privados, tomadas de decisão apropriadas às questões levantadas na avaliação. Podem-se citar como os principais métodos de avaliação de impacto ambiental o ad hoc e a listagem de controle (check-list), sendo estes dois utilizados neste trabalho, além da matriz de interação, redes de interação e modelos de simulação (BARROW, 1997). 
Diante deste cenário, a legislação ambiental também vem sendo aprimorada, bem como os instrumentos de tutela ambiental que aplicam estas leis, como o Termo de Ajustamento de Conduta (TAC), aplicado pelo Ministério Público do Rio de Janeiro como instrumento de gestão ambiental na erradicação dos lixões no Estado. Este instrumento é aplicável em todas as formas de tutela ambiental, preventiva ou reparatória, comportando-se de maneira eficiente, uma vez que permite aos órgãos públicos legitimados à ação civil pública tomar do causador de danos a interesses difusos e coletivos o compromisso de que venha a adequar a sua conduta às exigências legais, mediante cominações, com eficácia extrajudicial (SAROLDI, 2005).

O Município de Volta Redonda, área de estudo deste trabalho, está localizado na Região Sul Fluminense do Estado do Rio de Janeiro e se enquadra na temática apresentada. Possuiu um lixão como local de disposição para seus resíduos que esteve em operação durante 25 anos. O lixão recebia 169,4 toneladas diárias (VALADÃO et al., 2012), o que ocasionou danos ambientais significativos nas suas áreas de influências e levou o Ministério Público do Rio de Janeiro a autuar a Prefeitura Municipal de Volta Redonda, aplicando-Ihe um TAC. Este trabalho buscou analisar os impactos ambientais na área do vazadouro municipal Volta Redonda após sua desativação, com o intuito de avaliar sua recuperação ambiental.

\section{MATERIAL E MÉTODOS}

\section{Área de estudo}

Criado pela Lei oㅡ 2185 de 17 de julho de 1954, o município de Volta Redonda (figura 1) é o mais populoso da região sul do Estado do Rio de Janeiro, com 263.659 mil habitantes (IBGE, 2016). Localiza-se no trecho médio do vale do rio Paraíba do Sul, entre as serras do Mar e da Mantiqueira, entre os paralelos $22^{\circ} 24^{\prime} 11^{\prime \prime}$ e $22^{\circ} 38^{\prime}$ de latitude sul e os meridianos

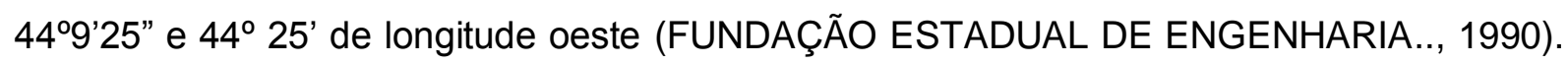
É, junto com os municípios Resende e Barra Mansa, uma das mais importantes economias da região.

A CSN, sem dúvida, foi responsável pela formação da identidade e pelo desenvolvimento econômico-social da cidade. Muitos moradores de cidades vizinhas e de outros estados, como São Paulo e Minas Gerais, migraram para Volta Redonda e possibilitaram, paralelamente, o crescimento de pequenos serviços e comércio no município. Contudo, em 1993, após a privatização da siderúrgica, a instalação da grave crise econômica e social fez com que a cidade procurasse novos rumos, com menor dependência da CSN. Hoje, segundo a Câmara de Dirigentes Lojistas de Volta Redonda (CDLVR), o 
município tornou-se um polo de prestação de serviços para a região na área de saúde e na área de educação, principalmente com a presença de universidades (MAGALHÃES; RODRIGUES, 2015).

Figura 1 - Mapa com características urbanas de Volta Redonda - RJ

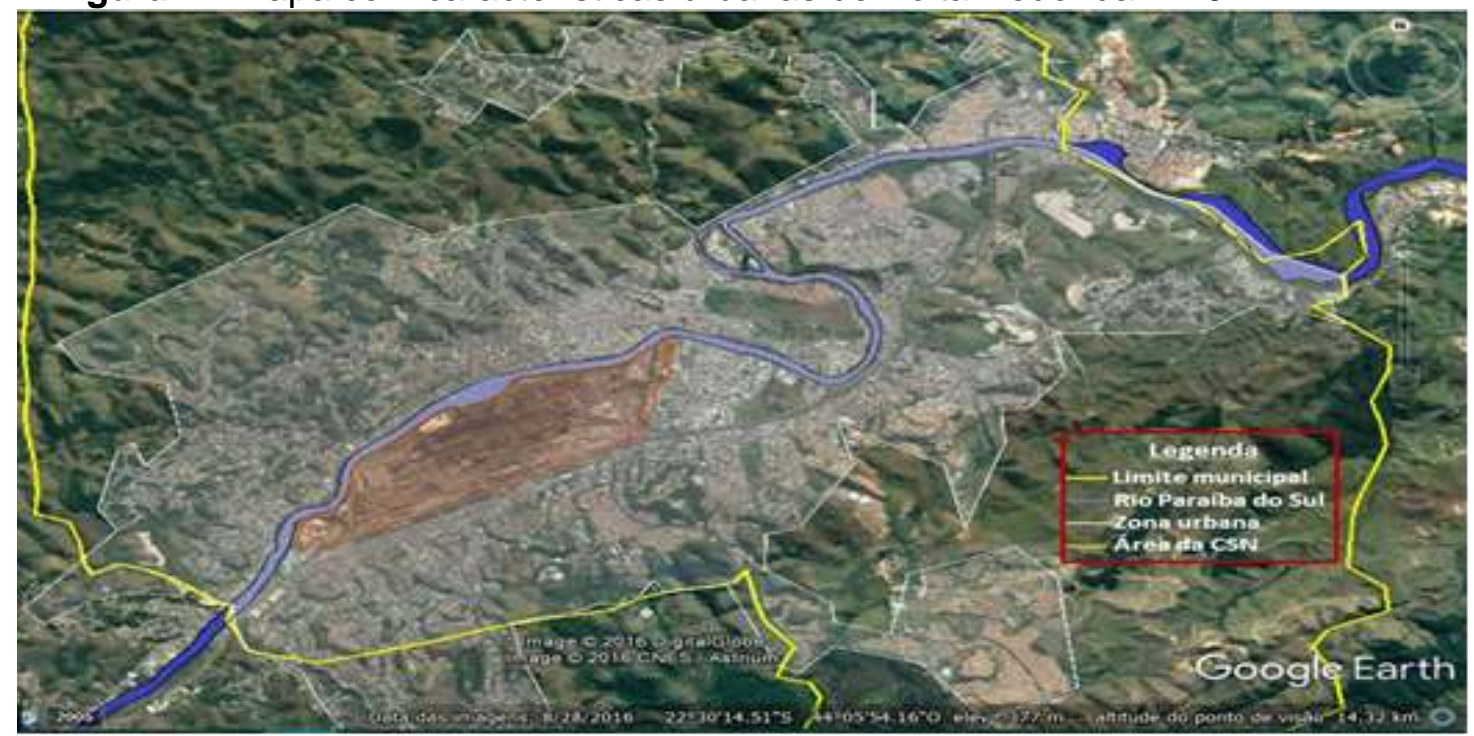

Fonte: Setta (2017).

O município de Volta Redonda é considerado um dos municípios mais poluídos do estado do Rio de Janeiro, e tem apresentado também, como outra fonte poluidora, o intenso tráfego de veículos que tem ocasionado diversas internações por doenças respiratórias, grande parte pela exposição dos indivíduos ao monóxido de carbono (PAIVA, 2014). Além disto, segundo Dias et al. (2003), a ocorrência de enchentes frequentes no verão está relacionada com a ocupação desordenada de encostas, margens de rios e fundos de vale, além do manejo inadequado do solo e a retirada da cobertura vegetal.

Diante de toda a expansão urbana que a cidade de Volta Redonda apresentava, a Prefeitura Municipal promoveu a construção de um depósito de resíduos em uma área cerca de dois quilômetros da Rodovia dos Metalúrgicos, rodovia que liga a área central do município à Rodovia Dutra. Além de Volta Redonda, por algum período, os municípios de Piraí e Rio Claro também utilizaram este mesmo local para disposição de seus resíduos (SETTA, 2016).

O vazadouro possui uma área total de 175.950 metros quadrados, sendo que a área do maciço do lixo é de 57.103 metros quadrados (INSTITUTO ESTADUAL DO AMBIENTE, 2015). De acordo com o Plano Diretor de Volta Redonda, aprovado em 2008 (Lei Municipal no. 4.441) (VOLTA REDONDA, 2008), o vazadouro está localizado no Setor Sul do município. $\mathrm{A}$ área era predominantemente rural, mas, nos últimos anos, tem correspondido a 
um dos principais eixos de crescimento da cidade, recebendo novos loteamentos e vias de acesso (PINTO et al., 2006). A Figura 2 mostra a localização do vazadouro no município.

Figura 2 - Localização do vazadouro no Município de Volta Redonda

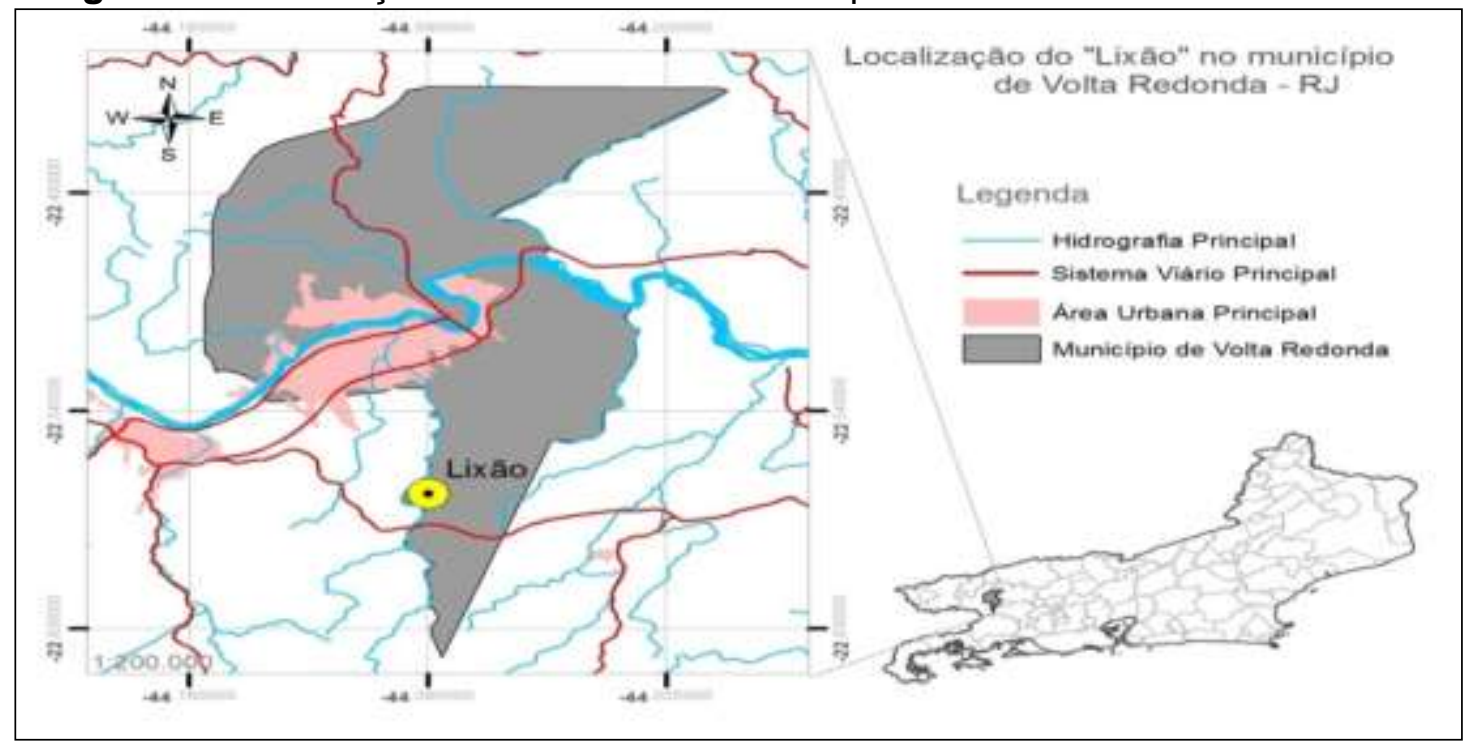

Fonte: organizado pelos próprios autores.

O vazadouro está inserido na Zona de Amortecimento da Área de Relevante Interesse Ecológico Floresta da Cicuta, a uma distância de 1,6 quilômetros, de acordo com a Resolução INEA № 71 de 18 de junho de 2013, Art. 1ํ, Parágrafo Único. Pela margem direita do vazadouro corre o Rio Brandão que, após cruzá-lo, chega à Floresta da Cicuta, recebe outros tributários que percorrem o município, como os córregos Cachoeirinha e Cafuá, e deságua no Rio Paraíba do Sul. Toda a malha hidrográfica inserida nos limites municipais de Volta Redonda tem o Rio Paraíba do Sul como seu corpo receptor final, que corresponde a $0,3 \%$ do total da bacia (FUNDAÇÃO ESTADUAL DE ENGENHARIA DO MEIO AMBIENTE, 1990, p. 32-35).

\section{Aplicação metodológica}

Os dados primários foram obtidos por meio de entrevistas com os representantes legais dos órgãos ambientais, tais como Secretaria de Meio Ambiente de Volta Redonda (SEMA-VR), Unidade Administrativa da ARIE Floresta da Cicuta e Instituto Estadual do Ambiente, e junto ao Ministério Público do Estado do Rio de Janeiro (MPRJ), mediante agendamento prévio, a fim de se obter possíveis informações como aspectos históricos do lixão, fatos legais que ocorreram para a desativação e características peculiares da área.

As vistorias à área de disposição dos resíduos foram acompanhadas por um técnico ambiental da prefeitura que contribuiu com informações sobre o histórico das operações e 
as atividades em andamento para a recuperação ambiental. Grande parte dos dados aqui apresentados foi baseada na inspeção visual do local, onde se buscou conhecer e avaliar os aspectos relacionados a:

- Infraestrutura existente;

- Características físicas e biológicas da área;

- Aspectos históricos da operação do lixão;

- Possíveis impactos ambientais ao solo, ar, água e saúde humana;

- Presença de animais.

Já os dados secundários foram obtidos por meio de pesquisas, estudos e trabalhos publicados em plataformas de pesquisas, como o Google Acadêmico, Scielo ou Periódicos Capes, em livros, revistas, legislação, repositórios acadêmicos, bibliotecas digitais de instituições de ensino e artigos científicos. Além disto, técnicas de SIG (Sistema de Informações Geográficas) foram utilizadas como ferramenta de geoprocessamento, como o software Quantum Gis (QGIS) e Google Earth, para possibilitar uma melhor interpretação da área de estudo.

Os métodos utilizados para identificar os impactos ambientais foram: Ad Hoc (método espontâneo) e Check-list (listagem de controle), na modalidade descritiva. O primeiro método proporciona de forma simples o entendimento dos impactos para o público em geral, mas apresenta alto grau de subjetividade, pois não considera aspectos quantitativos, apenas os qualitativos (RANIERI et al., 1998). No método Check-list são apresentados impactos nos recursos naturais (solo, água e ar, entre outros) por meio de listagens, porém não são estabelecidas relações de causa e efeito (ROVERE, 1992, p. 90).

A identificação dos tipos, causas e consequências da degradação na área de estudo foi realizada a partir dos impactos ambientais significativos identificados, obtendo auxílio de pesquisas em estudos ambientais acadêmicos e técnicos em áreas semelhantes.

\section{RESULTADOS E DISCUSSÃO}

\section{Análise do processo de remediação ambiental do vazadouro}

A disposição irregular de resíduos ocorreu de 1987 até 2012 (figura 3). O local serviu de deposição para o lixo domiciliar e industrial, do serviço de limpeza pública e dos serviços

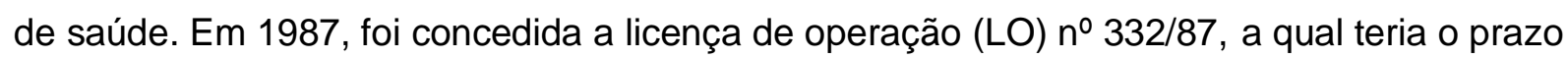
de expiração em 1992. Sua renovação não foi aprovada pela FEEMA (atual INEA), pois as exigências impostas pelo órgão ambiental não foram atendidas, mas as operações continuaram e, no ano de 2003, foi movida uma Ação Civil Pública, no $0002992-$ 48.2003.4.02.5104, pelo MPF e MPRJ contra a Prefeitura Municipal de Volta Redonda e o 
Depósito de Papel São Gabriel (empresa proprietária do terreno onde fica o vazadouro), na qual os réus foram responsabilizados pelas questões de remediação e encerramento.

Figura 3 - Disposição de resíduos no vazadouro em 2007

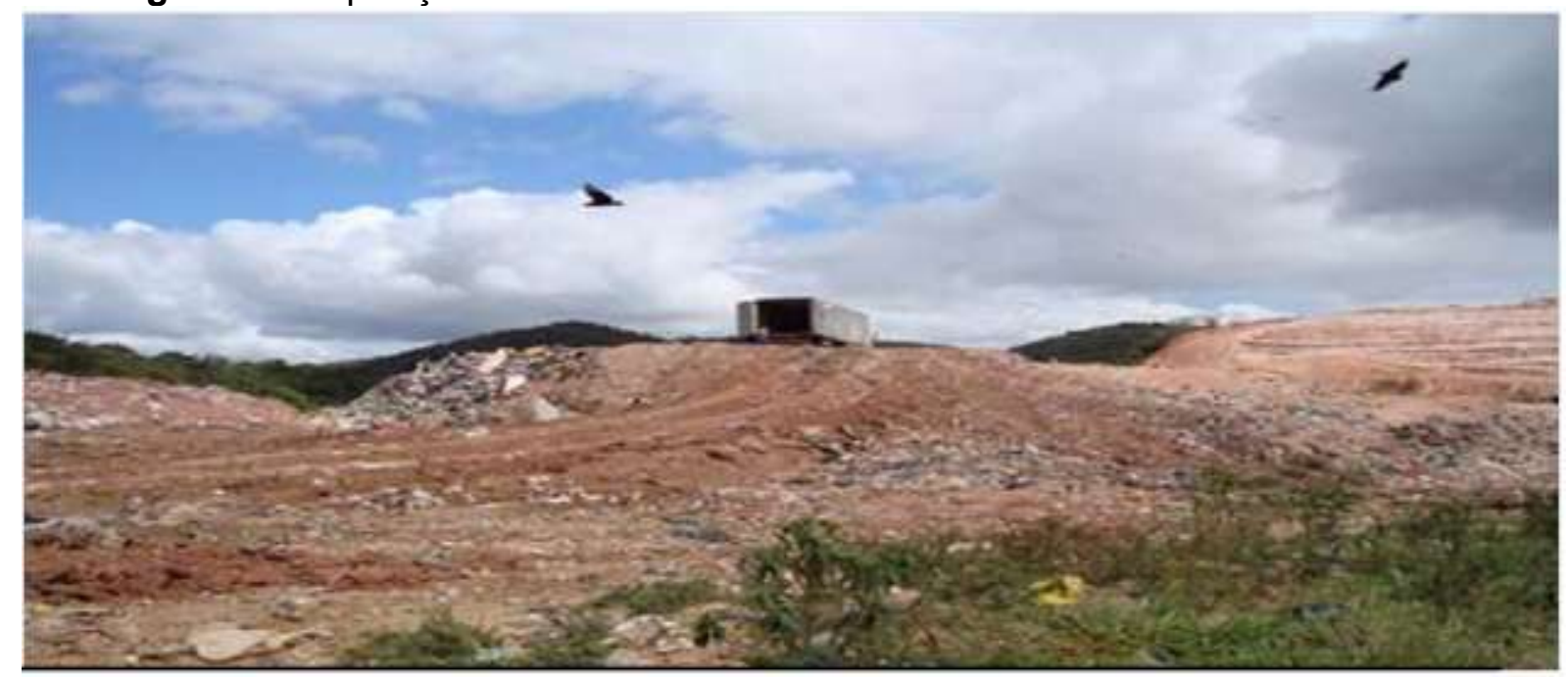

Fonte: Lopes (2016).

Em 2005, a Prefeitura Municipal de Volta Redonda foi acionada pelo MPF para assinar um TAC, número 2003.5104002992-9. Além disto, também assinaram o termo o MPRJ, Ministério Público do Trabalho (MPT), a FEEMA, o IBAMA e a empresa proprietária do terreno (MINISTÉRIO PÚBLICO FEDERAL, 2016). No entanto, desde então, a Prefeitura Municipal de Volta Redonda tem encontrado dificuldades para atender as ações impostas pelo TAC.

Houve discussões, entre a Prefeitura Municipal de Volta Redonda e os municípios de Pinheiral, Rio Claro, Barra do Piraí (somente o bairro Califórnia) e Barra Mansa, para formar um consórcio e construir um Centro de Tratamento de Resíduos (CTR) regional para processamento e destinação final de resíduos domiciliares, de serviços públicos e resíduos de serviços de saúde. No entanto, posteriormente, Barra Mansa optou por construir um aterro sanitário próprio e, para isto, contou com apoio da Secretaria de Estado de Meio Ambiente (SEMA).

Em 2009, em atendimento ao que foi estabelecido em uma reunião realizada no Ministério Público Federal, foi encaminhada pelo INEA uma orientação técnica de forma a nortear as ações emergenciais a serem executadas no vazadouro municipal. Em 2011, o Ministério Público, o INEA e o Instituto Chico Mendes de Conservação da Biodiversidade (ICMBio) cobraram ações mais concretas e efetivas por parte do município para o cumprimento do TAC. Assim sendo, algumas medidas foram tomadas, como: projetos de remediação com as revisões solicitadas pelo INEA, para a obtenção da autorização Licença de Operação e Recuperação (mais de dois projetos foram rejeitados pelo INEA); obras de 
melhorias no lixão evitando o descarte de chorume no Rio Brandão; compra da autoclave, equipamento que faz a esterilização de resíduos de serviço de saúde (RSS); e contratação de empresa para estudo locacional de nova área para instalação do CTR, que até a presente data ainda não foi decidido.

No ano de 2011, no Ministério Público Federal, foi relatado que em razão do descumprimento do TAC, por parte do Município de Volta Redonda, foram ajuizadas mais duas ações civis públicas contra o município (Processo 2010.51.04.001168-1 e 2003.51.04.002535-3), relacionadas, respectivamente, aos itens 1.8 (tratamento do chorume) e 2.1 (projeto de adequação ambiental da área do lixão). Na ocasião, o procurador da república Dr. Rodrigo da Costa Lines determinou algumas recomendações, inclusive que - INEA deveria notificar o município sobre o cumprimento das determinações do TAC, e que, caso não cumprisse, deveria interditar o vazadouro.

Como o novo prazo estabelecido para atender as recomendações do procurador - que seria até o final de dezembro de 2011 - não foi cumprido, os resíduos sólidos domiciliares deveriam ser encaminhados para o CTR de Barra Mansa, o qual é operado pela empresa Haztec. Além disto, o procurador Rodrigo da Costa Lines determinou que os resíduos sólidos deveriam ser encaminhados para este CTR a partir do 28 de maio de 2012, o que foi cumprido na íntegra pelo município.

Em 2014, a decisão judicial (Processo 0001167-25.2010.4.02.5104), referente ao projeto de remediação do vazadouro e ao tratamento de chorume, aplicou uma multa pessoal ao prefeito do Município de Volta Redonda, na época Antônio Francisco Neto, por não atender às determinações do MPF. Isto fez com que o MPF emitisse uma notificação pelo não atendimento das condicionantes da Autorização Ambiental, emitida em dezembro de 2014 pelo INEA, e três autos de constatação à Prefeitura de Volta Redonda, os quais evidenciaram que a prefeitura ainda não havia solicitado a LAR (Licença Ambiental de Recuperação).

Em 2015, a P Prefeitura Municipal de Volta Redonda requereu a LAR ao Instituto Estadual do Ambiente (INEA), através do processo E-07/002.09815/2015, o qual estabeleceu medidas a serem implantadas objetivando a remediação do vazadouro e medidas mitigadoras a serem adotadas após o encerramento (INSTITUTO ESTADUAL DO AMBIENTE, 2015). As medidas imputadas pelo INEA encontram-se no Quadro 1. 
Quadro 1 - Medidas mitigadoras para remediação ambiental do vazadouro de Volta Redonda

\section{Medidas mitigadoras para o encerramento}

- O fechamento da área remediada com cerca e replantio onde não houver mata nativa;

- Readequação das instalações de apoio para segurança, fiscalização, e controle de veículos, equipamentos e pedestres;

- Implantação de sistema de drenagem de águas superficiais visando minimizar os fluxos de água no interior da massa aterrada e de seu entorno;

- Instalação de um sistema de monitoramento do maciço com placas de recalque e marcos superficiais;

- Implantação de sistema de monitoramento de águas superficiais, subterrâneas e - Encerramento da célula de Resíduos de Serviços de Saúde;

- Conformação de platôs e taludes;

- Encerramento da célula de aterro com recobrimento final das áreas aterradas com camada mínima de 0,50 metro de solo compactado, geomembrana e camada de no mínimo 0,40 metro de solo vegetal para garantir o recobrimento com vegetação nativa raízes não axiais;

- Instalação de um sistema de monitoramento do maciço com placas de recalque e marcos superficiais.

percolados.;

\section{Medidas mitigadoras após o encerramento}

- Implantar um queimador de gases com "flare" para coletar o biogás na massa de resíduos;

- Construção de uma fossa séptica, filtro anaeróbio e sumidouro para armazenar e tratar efluentes sanitários;

Fonte: Instituto Estadual do Ambiente (2015).

- Implantar sistema de drenagem e coleta de chorume, conduzindo-o por gravidade até tanques de acumulação;

- Implantar serviço de coleta municipal para resíduos domésticos e contratar empresa licenciada pelo INEA para coletar resíduos provenientes de fossa séptica/filtro anaeróbio.

\section{Avaliação dos Impactos Ambientais}

Neste trabalho, a avaliação dos impactos ambientais foi realizada aplicando-se os métodos ad hoc e check-list. A identificação e análise qualitativa dos efeitos decorrentes dos impactos na área de influência direta, que compreendeu um raio de 1 quilometro do maciço de lixo, tornou possível a classificação quanto ao seu valor, possibilidade de mitigação, incidência, significância, e reversibilidade, tendo a importância de reuni-los e inferir o grau do prejuízo que esta atividade oferece para o meio ambiente (Quadro 2 e Figura 4). 
Quadro 2 - Impactos Ambientais e Respectiva Classificação

\begin{tabular}{|c|c|c|c|c|c|c|}
\hline & \multicolumn{6}{|c|}{ Critérios de classificação } \\
\hline $\begin{array}{l}\text { Impactos } \\
\text { ambientais }\end{array}$ & Valor & Mitigação & Significância & Incidência & Reversibilidade & Fatores afetados \\
\hline $\begin{array}{c}\text { Poluição e/ou } \\
\text { contaminação do } \\
\text { solo }\end{array}$ & NE & M & $\mathrm{S}$ & $\mathrm{D}$ e I & Rv & $\begin{array}{l}\text { Solo, água, fauna, } \\
\text { flora e antrópico }\end{array}$ \\
\hline $\begin{array}{l}\text { Alteração nas } \\
\text { características } \\
\text { físicas do solo }\end{array}$ & NE & M & S & D e I & Rv & \multirow{3}{*}{ Solo, flora e fauna } \\
\hline $\begin{array}{c}\text { Alteração nas } \\
\text { características } \\
\text { químicas do solo }\end{array}$ & NE & M & S & D e I & Rv & \\
\hline $\begin{array}{c}\text { Alteração nas } \\
\text { características } \\
\text { biológicas do solo }\end{array}$ & NE & M & S & $\mathrm{D}$ e I & Rv & \\
\hline $\begin{array}{l}\text { Poluição e/ou } \\
\text { contaminação de } \\
\text { recurso hídrico }\end{array}$ & NE & M & $\mathrm{S}$ & $\mathrm{D}$ e I & Rv & $\begin{array}{l}\text { Água, antrópico, } \\
\text { fauna e flora }\end{array}$ \\
\hline $\begin{array}{l}\text { Alteração do } \\
\text { relevo }\end{array}$ & NE & NM & $\mathrm{S}$ & $\mathrm{D}$ & Ir & $\begin{array}{c}\text { Solo, relevo e } \\
\text { paisagem }\end{array}$ \\
\hline $\begin{array}{c}\text { Poluição e/ou } \\
\text { contaminação do } \\
\text { ar atmosférico }\end{array}$ & NE & M & S & Del & Rv & $\begin{array}{c}\text { Ar, antrópico, fauna e } \\
\text { flora }\end{array}$ \\
\hline $\begin{array}{l}\text { Redução ou perda } \\
\text { total da flora }\end{array}$ & NE & M & S & $\mathrm{D}$ & Rv & $\begin{array}{c}\text { Flora, fauna, } \\
\text { antrópico, ar, solo, } \\
\text { água e paisagem }\end{array}$ \\
\hline $\begin{array}{l}\text { Redução ou perda } \\
\text { total da fauna }\end{array}$ & NE & M ou NM & $\mathrm{S}$ & $\mathrm{D}$ & Rv ou Ir & \multirow{2}{*}{ Fauna } \\
\hline $\begin{array}{c}\text { Contaminação dos } \\
\text { animais }\end{array}$ & NE & M & $\mathrm{S}$ & D e l & Rv & \\
\hline $\begin{array}{c}\text { Impacto na saúde } \\
\text { pública }\end{array}$ & NE & M & $\mathrm{S}$ & Del & Rv & \multirow{3}{*}{ Antrópico } \\
\hline $\begin{array}{l}\text { Incômodo para a } \\
\text { vizinhança }\end{array}$ & NE & M & $\mathrm{S}$ & $\mathrm{D}$ & Rv & \\
\hline $\begin{array}{c}\text { Desvalorização da } \\
\text { área do entorno }\end{array}$ & NE & M & NS & Del & Rv e/ou Ir & \\
\hline Legenda: NE - $N$ & & $\begin{array}{l}\text {; M - Mitigáv } \\
\text { Direta; Ir - I }\end{array}$ & vel; NM - Não m & $\begin{array}{l}\text { hitigável; S - s } \\
\text { eversível; Ir - }\end{array}$ & $\begin{array}{l}\text { significativo; NS - N } \\
\text { - Irreversível. }\end{array}$ & ăo significativo; D - \\
\hline
\end{tabular}

Fonte: organizado pelos próprios autores. 
Figura 4 - Classificação dos impactos ambientais

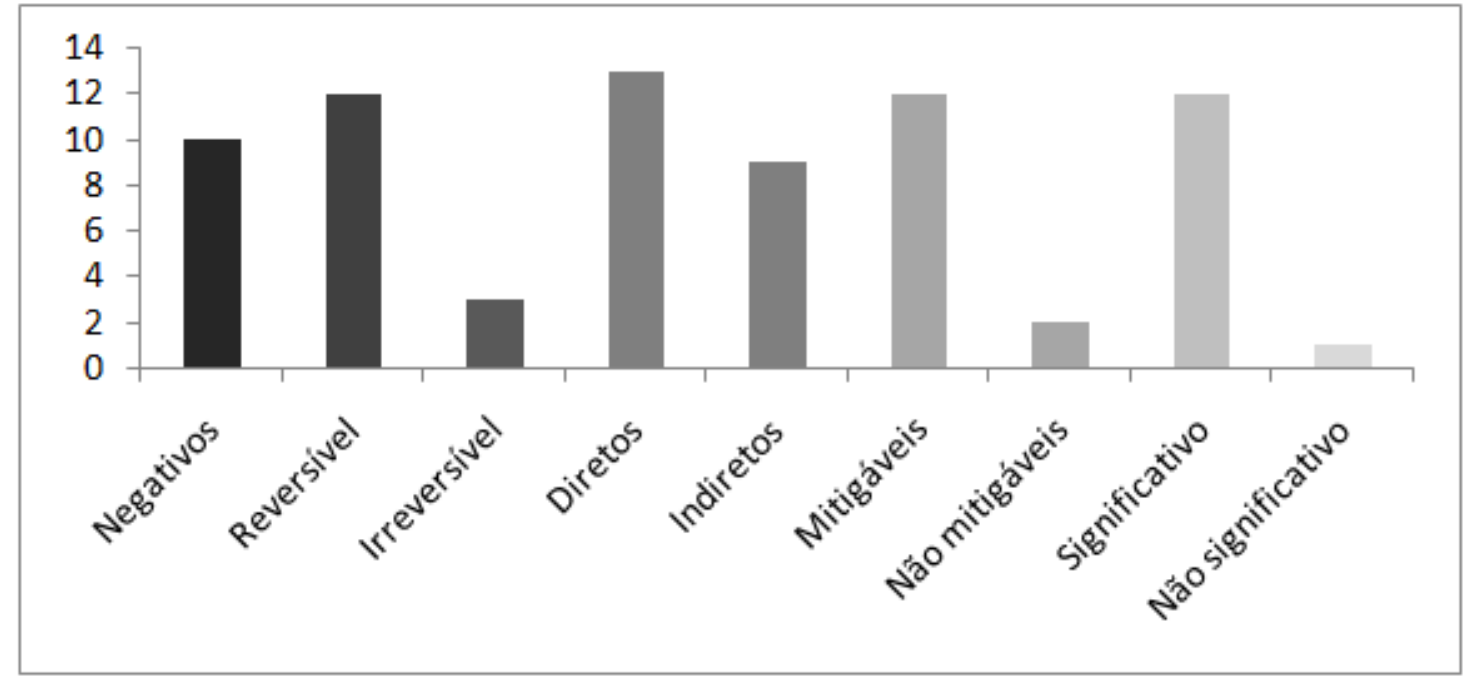

Fonte: organizado pelos próprios autores.

\section{Corpos hídricos}

Os efeitos de anos de deposição de resíduos no vazadouro são evidentes, até o momento, nos corpos hídricos encontrados no local. A liberação de efluentes e de compostos orgânicos, sobretudo os provenientes da degradação da matéria orgânica pelos micro-organismos, contaminaram os lagos, o que favoreceu o crescimento exacerbado de algas que formam verdadeiros "tapetes" na superfície destes lagos, como é possível observar na figura 5, referente à porção do lago a montante. Este fato indica um estado de eutrofização do lago, processo este que afeta o equilíbrio do ecossistema aquático, podendo impedir a entrada de luz solar no sistema, que é necessária para a fotossíntese, afetando toda cadeia trófica.

Figura 5 - Lago a montante com a superfície repleta de macrófitas (vistoria em maio de 2016)

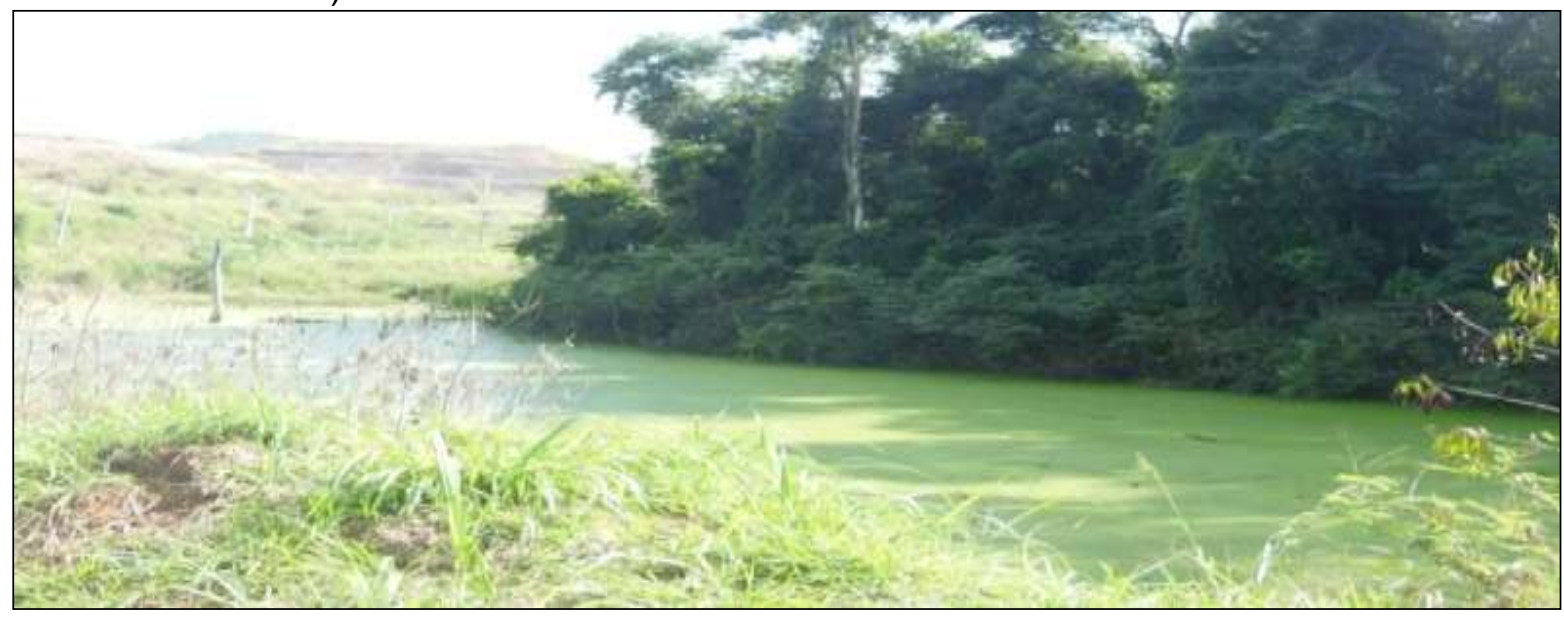

Fonte: Setta (2016). 
Lopes (2016) calculou em seu trabalho o índice de estado trófico para fósforo (IET $T_{\mathrm{PT}}$ ) nos lagos encontrados no vazadouro de Volta Redonda. Aplicou a equação modificada por Toledo Junior (1990), pois não havia dados referentes à clorofila a disponíveis. Os resultados encontrados por Lopes (2016) encontram-se no Quadro 3. A equação utilizada para o IET $T_{P T}$ se dá seguinte forma:

$$
\mathrm{IET}_{\mathrm{PT}}=10\{6-[\ln (80,32 / \mathrm{PT}) / \ln 2]\} ;
$$

tal que,

$\mathrm{IET}_{\mathrm{PT}}=$ índice de estado trófico para fósforo; $\mathrm{e}$ $\mathrm{PT}=$ concentração de fósforo total, medida à superfície da água $\left(\mu \mathrm{g} \cdot \mathrm{L}^{-1}\right)$.

Quadro 3 - Resultados do IET $T_{\text {PT }}$ para os lagos do vazadouro

$\begin{array}{ll}\text { Concentração de } & \text { Classificação } \\ \text { Fósforo }\left(\mu g . L^{-1}\right) & \text { IET }\end{array}$

$\begin{array}{cccc}\text { Lago a montante } & 2003 & 88,37 & \text { Hipereutrófico } \\ \text { Lago a jusante } & 480 & 79,71 & \text { Hipereutrófico }\end{array}$

Fonte: adaptado de Lopes (2016).

A classificação do estado de eutrofização em hipereutrófico ocorre, pois, segundo Toledo Junior (1990), os valores de IET $T_{P T}$ foram maiores que 7,4, indicando o maior grau de eutrofização possível para ser obtido. Por se encontrarem em áreas de baixo relevo e sem um exutório, a não ser a infiltração pelo solo, estes fatores acabam favorecendo a alta concentração de fósforo nos lagos (LOPES, 2016). Isto demonstra a necessidade do monitoramento contínuo da qualidade da água destes compartimentos para a biodiversidade local.

\section{Caracterização do chorume}

A massa de resíduos que está aterrada sofre decomposição pela ação dos microorganismos, que degradam a fração orgânica presente nos resíduos. A parte líquida, denominada chorume ou lixiviado, resultante da decomposição, percola pelo talude e, no seu ponto mais baixo, extravasa pelo solo. Na figura 6 pode-se observar o acúmulo de chorume na margem do talude, o qual é posteriormente succionado por uma bomba e transportado até o tanque armazenador.

Entretanto, no dia da visita, em maio de 2016, percebeu-se que havia um excesso de chorume acumulado na margem do talude, podendo haver um risco de percolação do líquido até o lago mais próximo ou até mesmo de infiltrar pelo solo. Com a chegada da estação do verão, este risco é potencializado devido à ação de chuvas mais intensas, o que 
demonstra a necessidade de maior acompanhamento, segurança e monitoramento desta atividade.

Figura 6 - Acúmulo de chorume na margem do talude (vistoria em maio de 2016)

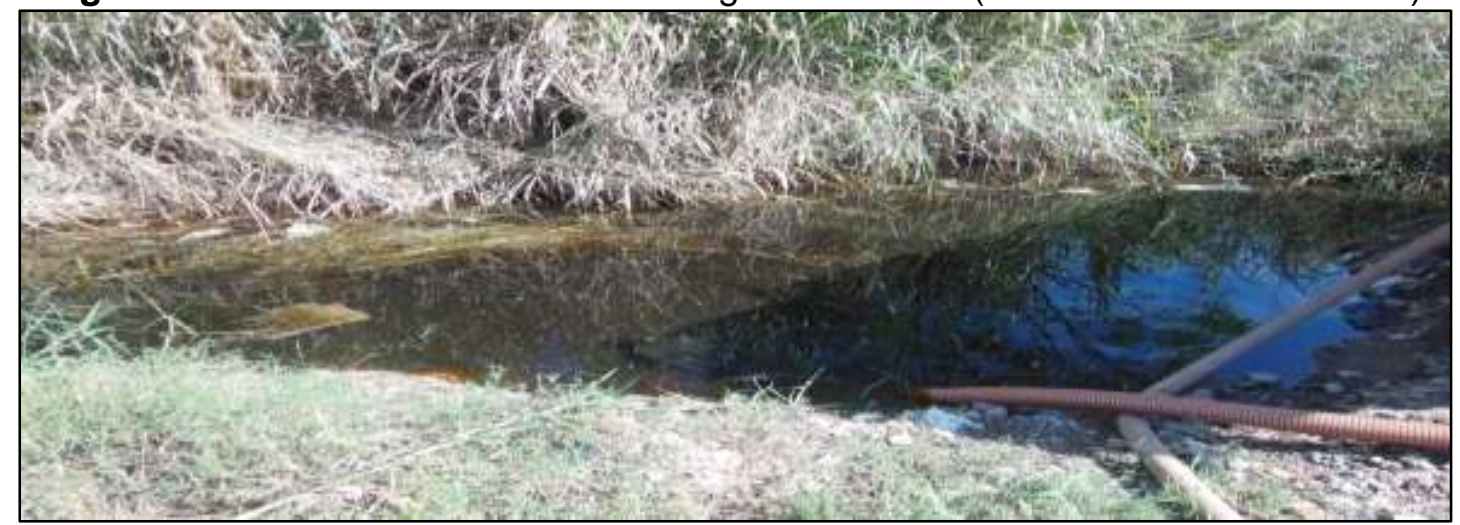

Fonte: Setta (2016).

As características químicas do chorume foram obtidas por meio de análises realizadas pela empresa Bioagri, contratada pela Prefeitura Municipal de Volta Redonda em 2013, a fim de identificar em qual fase de degradação se encontra a massa de resíduos já aterrada. Os resultados das análises encontram-se no Quadro 4.

Quadro 4 - Caracterização química do chorume

\begin{tabular}{|c|c|c|}
\hline Parâmetros & $\begin{array}{c}\text { Fase } \\
\text { metanogênica (> } \\
5 \text { anos) }\end{array}$ & Lixiviado \\
\hline $\mathrm{Ph}$ & $>7,5$ & 9,0 \\
\hline Demanda Química de Oxigênio (mg. $\mathrm{L}^{-1}$ ) & $<3.000$ & 1.802 \\
\hline Demanda Bioquímica de Oxigênio (mg.L- & $100-4000$ & 442 \\
\hline Relação $\mathrm{DBO}_{5} / \mathrm{DQO}$ & $<0,2$ & 0,24 \\
\hline Nitrogênio Amoniacal Total $\left(\mathrm{mg} \mathrm{L}^{-1}\right)$ & $3.000-4.000$ & 362 \\
\hline $\mathrm{NH}_{3}-\mathrm{N}\left(\mathrm{mg} \cdot \mathrm{L}^{-1}\right)$ & $>400$ & 238 \\
\hline Metais $\left(\mathrm{mg}^{\mathrm{L}} \mathrm{L}^{-1}\right)$ & $<2,0$ & $\begin{array}{c}\text { Cr: 0,22; Cd: }<0,001 ; \\
\text { Mn: } 0,532 ;\end{array}$ \\
\hline Ferro $\left(\mathrm{mg} \cdot \mathrm{L}^{-1}\right)$ & 6,3 & 4,2 \\
\hline Fósforo total $\left(\mathrm{mg} \mathrm{L}^{-1}\right)$ & 12 & 5,8 \\
\hline
\end{tabular}

Fonte: Lopes (2016).

A baixa concentração de amônia $\left(\mathrm{NH}_{3}-\mathrm{N}\right)$ é um bom indicador para atividade microbiana do aterro, visto que esta substância é tóxica e altas concentrações poderiam afetar o metabolismo dos micro-organismos degradadores da matéria orgânica. Este fato também se relaciona com alto valor do $\mathrm{pH}$ verificado, o que indica que $\mathrm{o}$ vazadouro encontra-se na sua fase metanogênica (SEGATO; SILVA, 2000).

Segundo Lopes (2016), a baixa concentração de Nitrogênio Amoniacal Total e também para a relação $\mathrm{DBO5/DQO}$ deve-se à construção de uma célula emergencial de disposição 
de resíduos em 2008, a qual permitiu a mistura do chorume desta célula com o outro coletado, oriundo da degradação dos resíduos mais antigos. No entanto, estes resultados não corroboram os valores encontrados no trabalho de Segato e Silva (2000), os quais verificaram altos valores para estes parâmetros onde havia mistura das contribuições das várias células que compõem o aterro sanitário de Bauru-SP.

\section{Paisagem}

A área de estudo, antes composta pela vegetação do Bioma Mata Atlântica, foi alterada por resíduos sólidos urbanos gerados no município de Volta Redonda-RJ, modificando sua paisagem e produzindo impacto visual.

O maciço de lixo aterrado se destaca na paisagem, mesmo com a presença de pouca vegetação ainda em crescimento sobre ele. Desde o início da operação, em 1987, a quantidade de resíduos depositado no local foi aumentando, o que formou este maciço. $\mathrm{Na}$ figura 7 é possível visualizar, através de imagens de satélite, o destaque do maciço na paisagem.

Figura 7 - Imagem satélite do maciço de lixo na paisagem

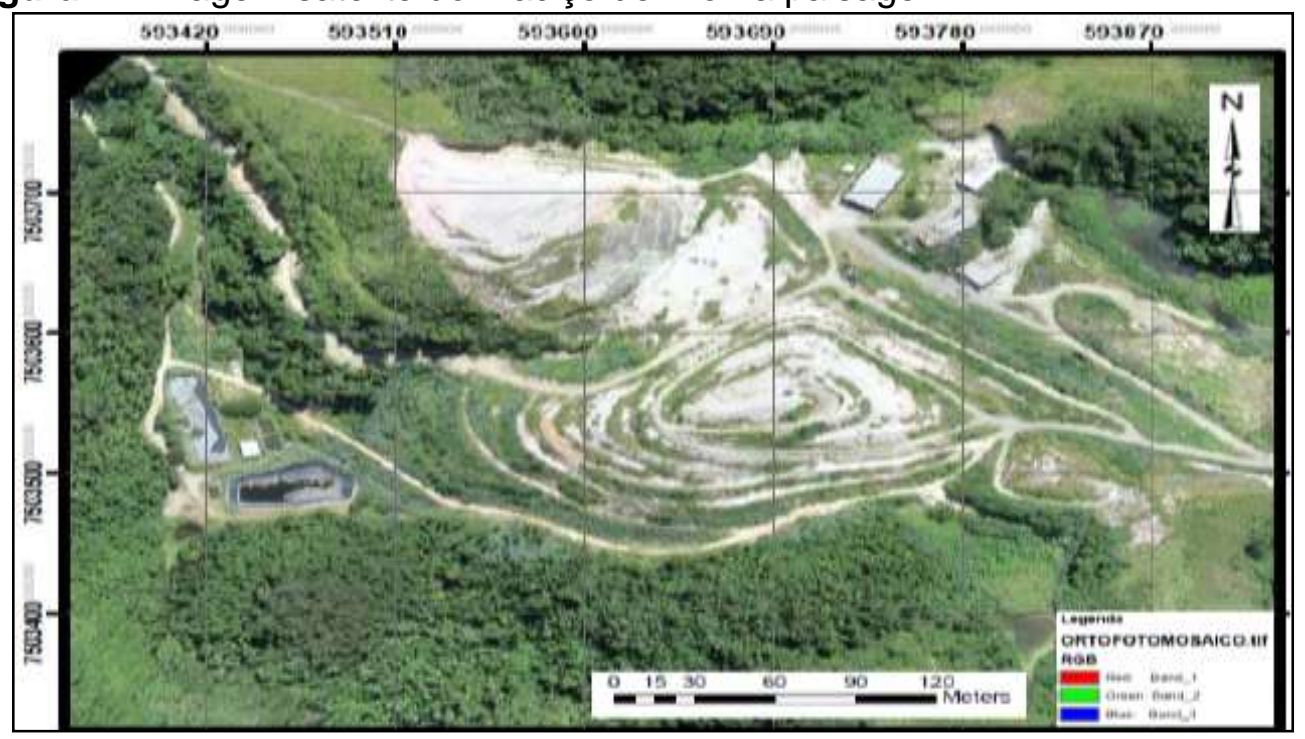

Fonte: Lopes (2016).

\section{Relevo}

O vazadouro encontra-se na Bacia Sedimentar de Volta Redonda, cuja unidade morfoescultural é o Tabuleiro de Bacias Sedimentares (DIAS; GOMES; GOES, 2003), formada principalmente por arenitos e argilitos, de origem Cenozóica. Esta bacia é circundada por rochas cristalinas de origem metamórfica e ígneas intrusivas, compondo uma 
importante feição geológica brasileira, o "Rift Continental do Sudeste do Brasil" (ALMEIDA; CARNEIRO, 1998).

Por meio da visita realizada ao vazadouro, foi possível identificar o perfil do solo encontrado, o qual é do tipo Argilossolo Vermelho-Amarelo, confirmado também no trabalho de Lopes (2016), como pode ser observado na figura 8. Este tipo de solo caracteriza-se por apresentar acumulação de argila no horizonte $\mathrm{B}$, com cores vermelho-amareladas devido à presença da mistura dos óxidos de ferro hematita e goethita. Apresenta baixa fertilidade natural, com reação fortemente ácida, e é profundo (SILVA; OLIVEIRA NETO, 2016).

Figura 8 - Imagem do solo e processos erosivos (vistoria em maio de 2016)

Fonte: Setta (2016).

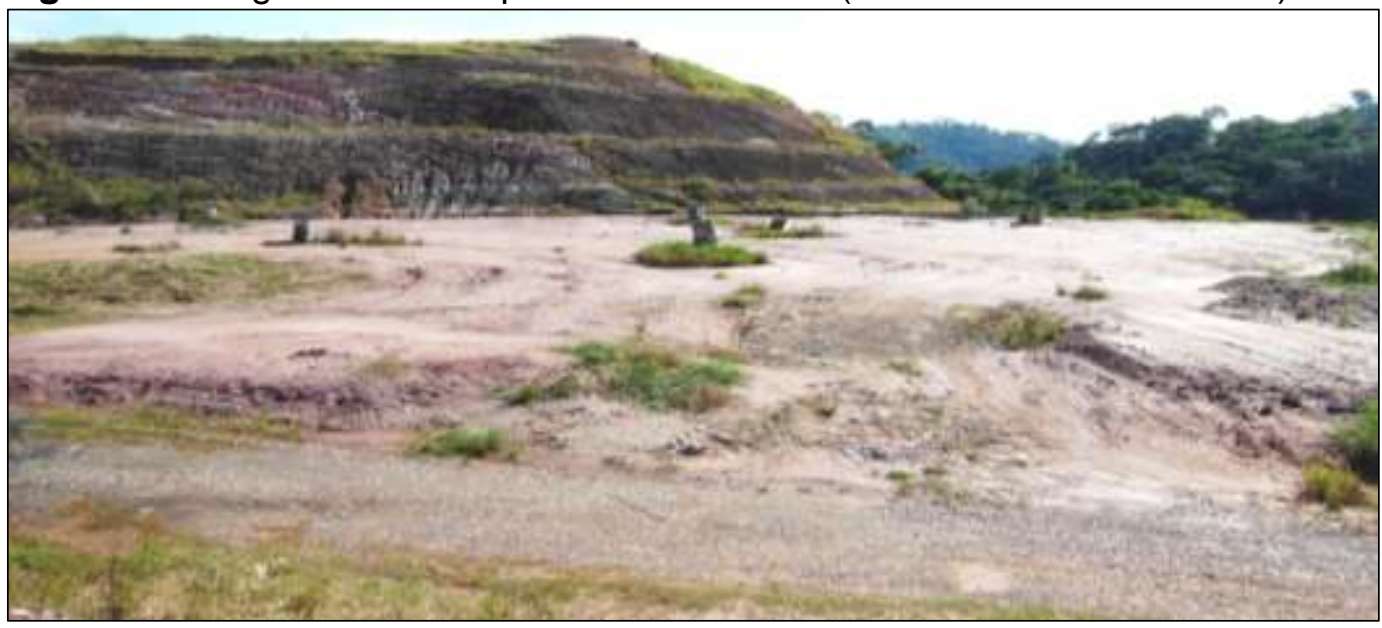

Conforme pode ser observado na figura 8, o solo ainda se encontra bastante erodido e com pouca vegetação estabelecida. Diante disto, percebe-se que a recuperação da qualidade do solo não foi monitorada e controlada ao longo dos anos, para evitar possíveis desmoronamentos de terra ou até mesmo o crescimento de plantas oportunistas. Vale alertar para a possibilidade da geração de mais chorume, sobretudo em períodos chuvosos, pois os desmoronamentos podem liberar ainda mais resíduos.

\section{Fauna e flora}

A vegetação encontrada no entorno do vazadouro é formada por espécies do Bioma Mata Atlântica, caracterizada como Floresta Estacional Semidecidual Submontana, com presença de árvores de médio e grande porte, pertencentes à Zona de Amortecimento da ARIE Floresta da Cicuta. Por se tratar, desta forma, de uma área de extensão desta unidade de conservação, é possível que no local do maciço de lixo houvesse espécies vegetais importantes para a ecologia local, como, por exemplo, o jequitibá (Cariniana legalis), figueira 
(Ficus cyclophylla) e canxim (Pachystroma longifolium) (INSTITUTO CHICO MENDES..., 2016).

No entanto, quanto à recuperação da vegetação na área do vazadouro, não se verificou atividades de reflorestamento, como o plantio de espécies nativas ou de mudas, como foi exigido na LAR (INSTITUTO ESTADUAL DO AMBIENTE, 2015), mas sim o processo de regeneração natural (sucessão ecológica secundária), com a presença de espécies herbáceas e arbustivas, como a embaúba (Cecropia pachystachya), e gramíneas, conforme a figura 9. Além disto, a espécie invasora encontrada em abundância foi o capim colonião (Panicum maximum Jacq) (MATOS; PIVELLO, 2009), principalmente nos taludes e nas regiões de borda do vazadouro, conforme a figura 10 .

Figura 9 - Embaúba (vistoria em maio de 2016)

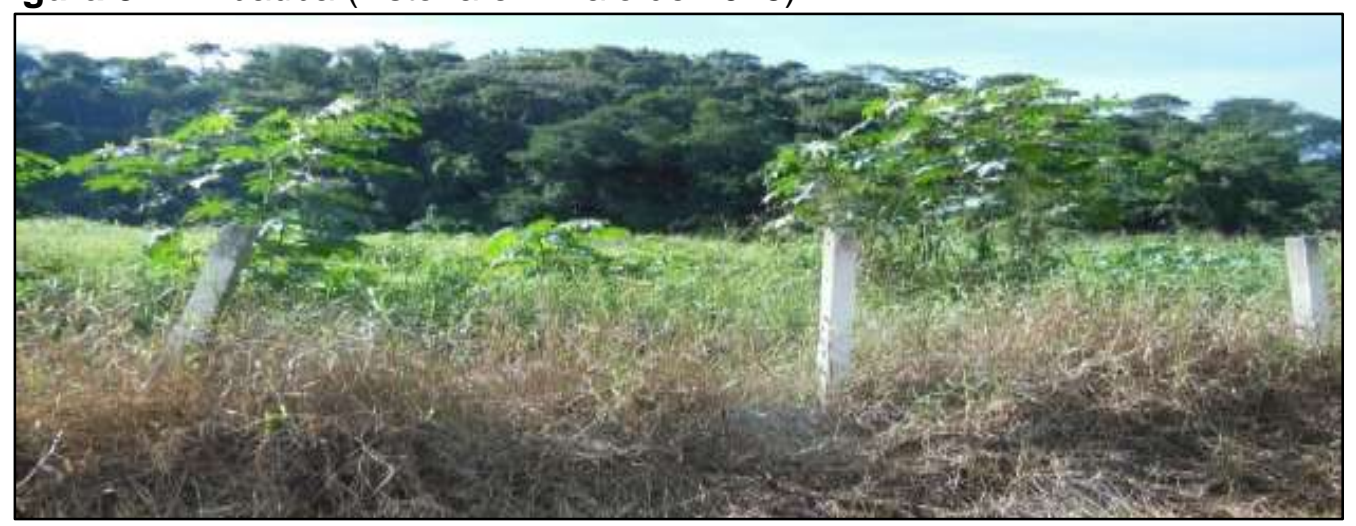

Fonte: Setta (2016).

Figura 10 - Capim colonião (vistoria em maio de 2016)

Fonte: Setta (2016).

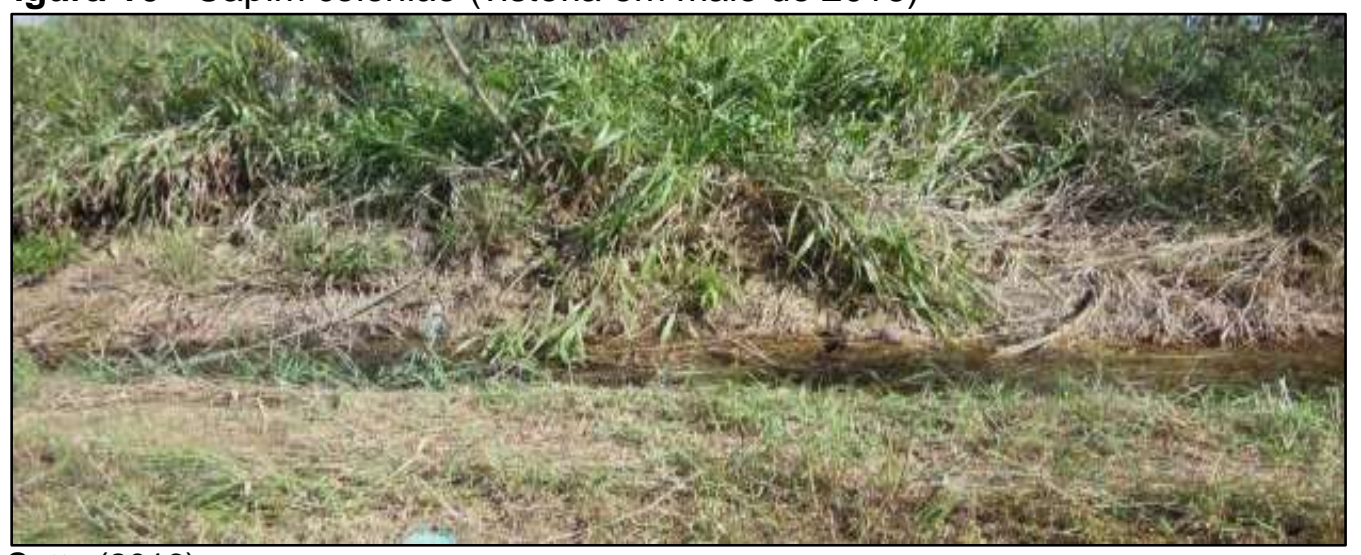

Em relação à fauna, foram observados representantes da avifauna, como o marreco do-sul (Netta erythrophtalma), os quais estavam se alimentando no lago a montante do vazadouro, e animais sinantrópicos, como cães domésticos (Canis lupus familiaris), conforme as figuras 11 e 12, respectivamente. Vale ressaltar que apesar de não ter se verificado uma biodiversidade expressiva no local, não foram encontradas espécies 
oportunistas de aves, como o carcará e urubu, as quais se alimentam de restos de alimentos e detritos orgânicos presentes nos resíduos. Provavelmente o aterramento dos resíduos diminuiu a disponibilidade de alimento para estas aves, forçando-as a encontrar alimento em outro local.

Figura 11 - Marreco-do-sul (vistoria em maio de 2016)

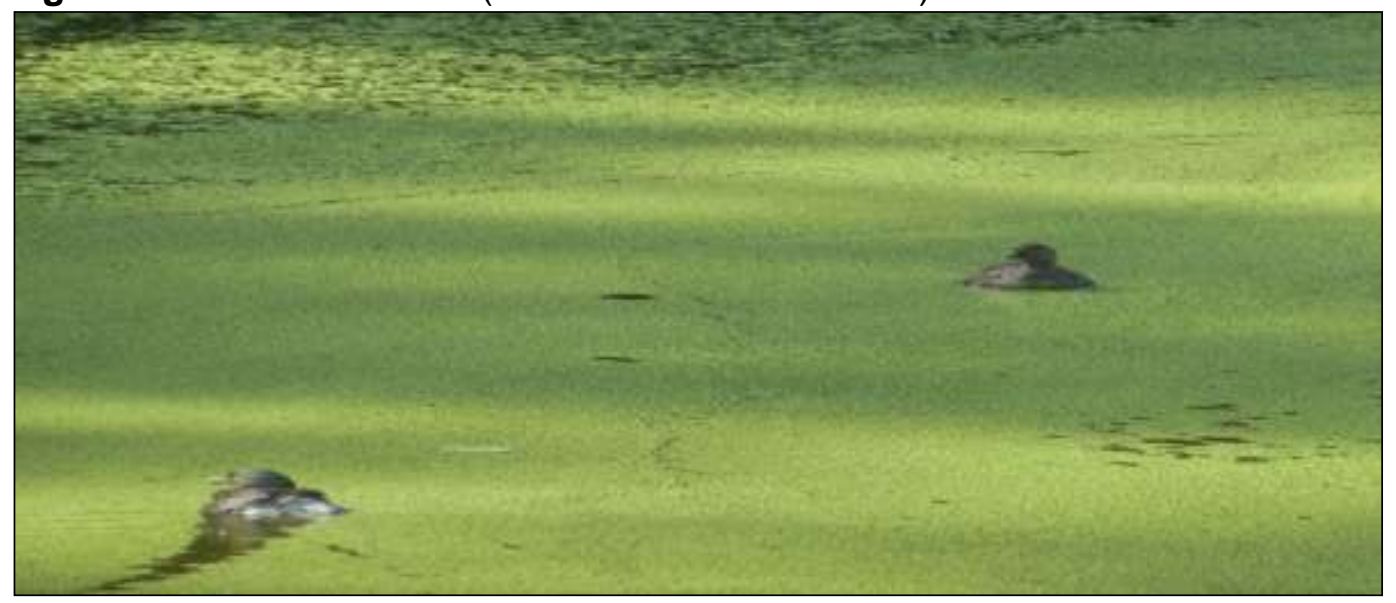

Fonte: Setta (2016).

Figura 12 - Cão doméstico (vistoria em maio de 2016)

Fonte: Setta (2016).

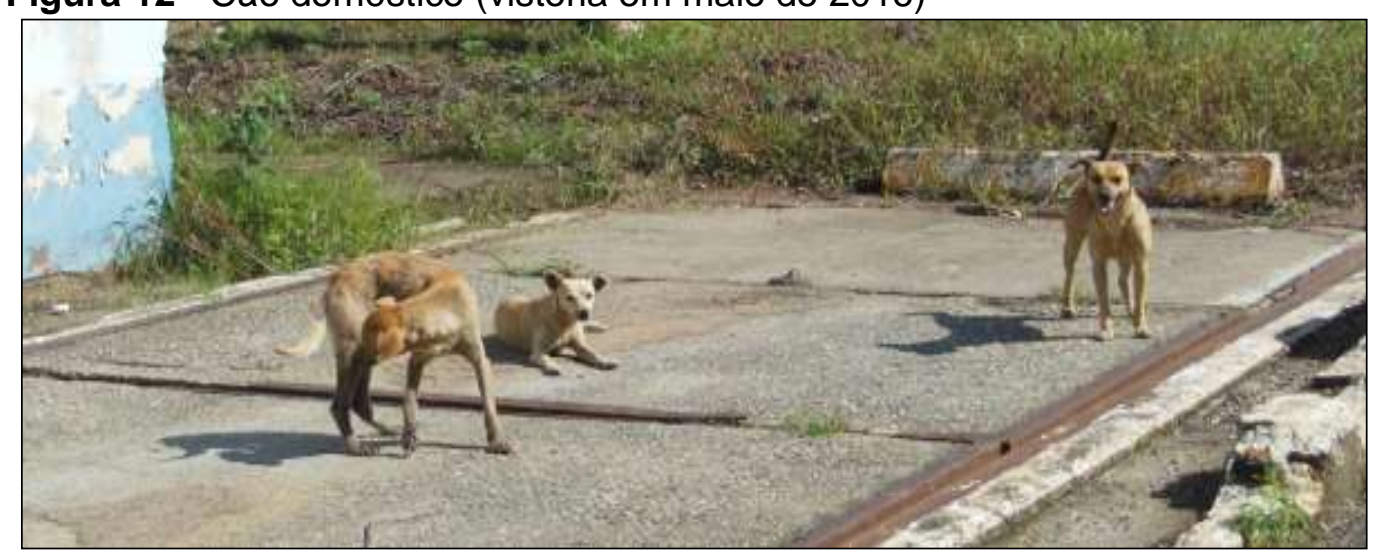

\section{CONCLUSÃO}

A disposição de resíduos em aterros caracteriza-se por uma atividade de alto potencial poluidor, uma vez que a produção de resíduos sólidos urbanos é um processo muito heterogêneo, devido à sua composição se derivar de resíduos domésticos ou industriais, de áreas pobres ou ricas, de coleta generalizada ou seletiva. Sendo assim, ocorre o risco da mistura com os resíduos orgânicos e materiais perigosos, os quais exigem maiores medidas de segurança para o gerenciamento.

O processo de remediação ambiental do vazadouro de Volta Redonda perdurou por muitos anos e trouxe sérias consequências ao meio ambiente. $O$ exemplo do município 
demonstra que a questão do tratamento adequado para o lixo urbano não é vista, até o momento, como prioridade pelas autoridades competentes, sobretudo pela administração pública, a qual adotou medidas de pouca ou nenhuma eficácia quanto à remediação dos passivos ambientais, pois o vazadouro ainda não foi totalmente remediado.

Os resultados referentes aos dados físico-químicos dos corpos hídricos e do chorume demonstram um quadro relativamente superficial da sua degradação. Como a Prefeitura Municipal de Volta Redonda não buscou atender as condicionantes impostas pelo TAC desde 2005, os dados foram apenas obtidos no ano de 2013, após diversas outras exigências legais do MPF e INEA, não sendo, portanto, muito representativos mediante os 25 anos de operação do vazadouro. Por isto, recomenda-se a continuação do monitoramento ambiental da qualidade da água dos corpos hídricos e do chorume, de forma a garantir melhores condições ambientais ao local e segurança à população.

Considerando ainda a possibilidade de contaminação e/ou poluição do lençol freático, devido à disposição de resíduos, estudos e análises referentes a sua qualidade foram realizados por uma empresa de consultoria ambiental contratada pela Prefeitura Municipal de Volta Redonda, em 2013, mas ainda não estão disponíveis para a população. Segundo a Secretaria Municipal de Meio Ambiente de Volta Redonda, a indisponibilidade destas informações se deve ao trâmite do projeto de remediação ambiental do vazadouro ainda na Justiça. Logo, este aspecto ambiental, imprescindível para este tipo de trabalho, não foi possível de ser discutido com profundidade.

Apesar do responsável legal do Município de Volta Redonda ter sido acusado e julgado por não cumprir as condicionantes ambientais da Licença Ambiental de Recuperação, a atuação do órgão estadual demonstrou-se pouco efetiva em fiscalizar o cumprimento das condicionantes, de exigir da prefeitura municipal a regularização do processo de licenciamento da operação e a remediação dentro do prazo, o que poderia ter reduzido os danos ambientais. Desta forma, o caso de Volta Redonda mostra as mesmas dificuldades apresentadas pela maioria dos municípios brasileiros, seja técnica, estrutural ou financeira, em atender a legislação ambiental.

\section{REFERÊNCIAS}

PANORAMA dos resíduos sólidos no Brasil 2015. São Paulo, SP: Associação Brasileira de Empresas de Limpeza Pública e Resíduos Especiais, 2016.

SILVA, Maria Sonia Lopes da; OLIVEIRA NETO, Manoel Batista de. Argilossolos vermelho-amarelos. Disponível em:

<http://www.agencia.cnptia.embrapa.br/gestor/territorio_mata_sul_pernambucana/arvore/CO NT000gt7eon7k02wx7ha087apz2axe8nfr.html>. Acesso em: 22 out. 2016. 
ALMEIDA, F. F. M.; CARNEIRO, C. D. R. Origem e evolução da Serra do Mar. Revista Brasileira de Geociências, São Paulo, n. 2, v. 28, p. 135 - 180, 1998.

ASSAD, L.; SIQUEIRA, T. Lixões continuam por toda parte. Revista Ciência e Cultura, Campinas, v. 68, n. 2, p. 1-3. São Paulo,SP, abr./jun. 2016.

BARROW, C. J. Environmental and social impact assessment: an introduction. New York: Oxford University Press, 1997.

ANÁLISE das diversas tecnologias de tratamento e disposição final de resíduos sólidos no Brasil, Europa, Estados Unidos e Japão. Jaboatão dos Guararapes: Universidade Federal de Pernambuco, 2012. (Pesquisa Científica / BNDES, FEP, n. 02/2010).

BRASIL. Lei Federal $\mathbf{n}^{\circ}$ 12.305, de 2 de agosto de 2010. Institui a Política Nacional de Resíduos Sólidos. Disponível em: <http://www.planalto.gov.br/ccivil_03/_ato20072010/2010/lei/l12305.htm >. Acesso em: 18 out. 2016.

BRASIL. Ministério do Meio Ambiente. Conselho Nacional do Meio Ambiente. Resolução n. 1, de 23 de janeiro de 1986. Dispõe sobre critérios básicos e diretrizes gerais para o Relatório de Impacto Ambiental - RIMA. Diário Oficial [da] República Federativa do Brasil, Brasília, D. F., 17 fev. 1986. Seção 1, p. 2548-2549.

BRASIL. Lei Federal $n^{\circ}$ 6.938, de 31 de agosto de 1981. Dispõe sobre a Política Nacional do Meio Ambiente. Disponível em: <http://www.planalto.gov.br/ccivil_03/leis/l6938.htm>. Acesso em: 18 out. 2016.

DIAS, J. E.; GOMES, O. V. O.; GOES, M. H. B. Áreas de riscos de enchentes no Município de Volta Redonda: uma aplicação por geoprocessamento. Revista Caminhos de Geografia, Uberlândia, v. 2, n. 10, p. 13 - 25, set. 2003.

FUNDAÇÃO ESTADUAL DE ENGENHARIA DO MEIO AMBIENTE - FEEMA. Perfil do Município de Volta Redonda. Volta Redonda, 1990.

GOUVEIA, N. Resíduos sólidos urbanos: impactos socioambientais e perspectiva de manejo sustentável com inclusão social. Revista Ciência \& Saúde Coletiva, Rio de Janeiro, v. 17, n. 6, p. 1503 - 1510, 2012.

IBGE. Projeção da população do Brasil e das Unidades da Federação. Disponível em: <http://www.ibge.gov.br/apps/populacao/projecao/>. Acesso em: 18 out. 2016.

INSTITUTO CHICO MENDES DE CONSERVAÇÃO DA BIODIVERSIDADE - ICMBio. Plano de manejo da ARIE Floresta da Cicuta. Brasília, 2016.

INSTITUTO ESTADUAL DO AMBIENTE - INEA. Parecer Técnico de Licença Ambiental de Recuperação n. SUPMEP 02.09.15. Rio de Janeiro, RJ, 2015.

VALADÃO, I. C. R. P. et al. Elaboração do perfil difusivo de íons inorgânicos $\mathrm{Cl}-\mathrm{K}+\mathrm{e} \mathrm{Na+}$ presentes no solo e no lixiviado do aterro de Volta Redonda - RJ. In: CONGRESSO BRASILEIRO DE MECÂNICA DOS SOLOS E ENGENHARIA GEOTÉCNICA, 16., 2012, Porto de Galinhas, PE. Anais... Porto DE Galinhas: ABMS, 2012. p. 1 - 3.

JUNKES, M. B. Procedimentos para aproveitamento de resíduos sólidos urbanos em municípios de pequeno porte. 2002. Dissertação (Mestrado em Engenharia de Produção) - Universidade Federal de Santa Catarina, SC, Santa Catarina.

LOPES, G. A. Caracterização do aterro controlado de Volta Redonda por meio de índices de qualidade e geotecnologia. 2016. Dissertação (Mestrado em Tecnologia Ambiental) - Universidade Federal Fluminense, Volta Redonda, RJ.

MAGALHÃES, C. H.; RODRIGUES, M. I. Volta Redonda pós-privatização da CIA. Siderúrgica Nacional: a crise de uma cidade monoindustrial em busca de uma nova identidade econômica. Revista Brasileira de Gestão e Desenvolvimento Regional, Taubaté, v. 11, n. 2, p. 359 - 378, maio/ago. 2015. 
MATOS, D. M. S.; PIVELLO, V. R. O impacto das plantas invasoras nos recursos naturais de ambientes terrestres: alguns casos brasileiros. Revista Ciência e Cultura, São Paulo, SP, v. 61, n. 1, p. $1-4,2009$.

MINISTÉRIO PÚBLICO FEDERAL. MPF quer cessar danos ambientais do lixão de Volta Redonda. Ação contra o município busca cumprimento de TAC. Disponível em: <http://noticias.pgr.mpf.mp.br/noticias/noticias-dosite/copy_of_meio-ambiente-e-patrimoniocultural/mpf-rj-quer-cessardanos-ambientaisdo-lixao-de-volta-redonda>. Acesso em: 22 nov. 2016.

PAIVA, R. F. P. S. Morbidade hospitalar por doenças associadas à poluição do ar na cidade de Volta Redonda, Rio de Janeiro: casos e custo econômico. Caderno Saúde Coletiva, Rio de Janeiro, v. 22, n. 2, p. 127-133, 2014.

PINTO, S. T. et al. Análise temporal de feições erosivas e escorregamentos no Município de Volta Redonda - RJ. In: SIMPÓSIO NACIONAL DE GEOMORFOLOGIA, 6., 2006, Goiânia, GO. Anais... Goiânia: UFG, 2006. p. 3 - 6.

VOLTA REDONDA. Prefeitura Municipal. Plano Diretor Participativo de Volta Redonda: Lei Municipal $n^{\circ}$ 4.441/2008. 2008. Disponível em: <www.voltaredonda.rj.gov.br>. Acesso em: 24 jan. 2017.

RANIERI, S. B. L. et al. Aplicação de índice comparativo na avaliação do risco de degradação das terras. Revista Brasileira de Ciência do Solo, Viçosa, v. 22, p. 751 - 760, 1998.

ROVERE, E. L. L. Metodologia de avaliação de impacto ambiental. Instrumentos de planejamento e gestão ambiental para a Amazônia, Pantanal e Cerrado: demandas e propostas. Brasília: IBAMA, 1992. Documento final.

SAROLDI, M. J. L. A. Indicadores de monitoramento ambiental dos termos de ajustamento de conduta na gestão de resíduos sólidos no Estado do Rio de Janeiro. In: CONGRESSO BRASILEIRO DE ENGENHARIA SANITÁRIA E AMBIENTAL, 23., 2005, Campo Grande, MS. Anais... Campo Grande: ABES, 2005. p. 1 - 3.

SEGATO, L. M.; SILVA, C. L. Caracterização do chorume do aterro sanitário de Bauru. In: CONGRESSO INTERAMERICANO DE ENGENHARIA SANITÁRIA E AMBIENTAL, 27. 2000, Porto Alegre, RS. Anais... Porto Alegre: ABES, 2000. p. 4 - 9.

SETTA, B. R. S. Análise preliminar da degradação ambiental na área do lixão do Município de Volta Redonda, RJ. In: SIMPÓSIO DE GESTÃO AMBIENTAL E BIODIVERSIDADE, 5., 2016, Três Rios. Anais... Três Rios: Universidade Federal Rural do Rio de Janeiro, Instituto Três Rios, 2016. p. 213 - 215.

SETTA, B. R. S. Telhados verdes como políticas públicas ambientais para o Município de Volta Redonda, RJ. Revista LABVERDE, São Paulo, v. 8, n. 1, p. 17 - 18, mar. 2017.

TOLEDO JUNIOR, A. P. Informe preliminar sobre os estudos para obtenção de um índice para avaliação simplificada do estado trófico de reservatórios de regiões quentes tropicais. São Paulo: CETESB, 1990. (Relatório Técnico, p. 22 - 34).

Recebido: fevereiro de 2017. Aceito: março de 2018. 